DOI 10.37882/2223-2982.2020.12-3.11

\title{
СТРУКТУРНЫЙ АНАЛИЗ СЛОЖНЫХ КОМПЛЕКСОВ РЫБОЛОВНОЙ ТЕМАТИКИ В ДИАЛЕКТАХ СЕЛЬКУПСКОГО ЯЗЫКА
}

\section{STRUCTURAL ANALYSIS \\ OF THE FISHING COMPLEX NAMING UNITS IN THE SELKUP DIALECTS}

\section{A. Devyakovich}

Summary: The article provides a structural analysis of fishing complex naming units, which are used to designate the specific objects of the Selkup fishery. In the Selkup dialects complex naming units are divided into two types: compound names and word combinations, the main difference of which lies in the degree of semantic unity between the unit components. Upon the results of the structural analysis, the formation patterns for compound names and word combinations are derived from.

Keywords: Selkup dialects, fishing vocabulary, complex naming unit, compound name, word combination, structural analysis, unit formation pattern.

\author{
Девякович Анна Александровна \\ Соискатель, Томский государственный \\ педагогический университет \\ annadeviakovich@gmail.com
}

Аннотация: В статье приводится структурный анализ сложных комплексов рыболовной тематики, которые используются для обозначения специфичных реалий рыболовства, характерных для хозяйственного уклада селькупов. В диалектах селькупского языка разделяют два вида сложных комплексов: составные наименования и словосочетания, основное отличие которых заключается в степени семантического единства между компонентами комплекса. По результатам проведённого анализа обозначаются модели образования составных наименований и словосочетаний рыболовной тематики.

Ключевые слова: диалекты селькупского языка, лексика рыболовства, сложный комплекс, составное наименование, словосочетание, структурный анализ, модель образования.
$\mathrm{P}$ ыболовная лексика диалектов селькупского языка связана с важнейшим видом хозяйственной деятельности селькупов и относится к древнейшему лексическому пласту. Одной из отличительных особенностей селькупской лексики рыболовства является обилие так называемых сложных комплексов, которые как правило, состоят из двух-трёх компонентов и выполняют функцию, типичную для имени существительного. Авторы «Очерков по селькупскому языку» к сложным комплексам относят собственно сложные слова и словосочетания с разной степенью семантической спаянности [4, с. 39]. В языковедческой литературе такие единицы называют по-разному: составные термины, составные названия, сложные наименования, терминологические сочетания, терминологические обороты, терминологические фразеологизмы [3, с. 119]. В контексте данного исследования для обозначения подобных сложных комплексов мы используем два термина - «составное наименование» и «словосочетание».

Следует разграничить эти два понятия. Согласно «Селькупско-русскому диалектному словарю» составное наименование - это аналитическая номинативная единица, которая строится по модели словосочетания, сохраняет раздельнооформленность и воспроизводится как одна номинативная единица $[9$, с. 6]. Полагаем, что основное отличие составного наименования от словосочетания заключается в более высокой степени его семантического единства, в то время как словосочетание представляет собой свободную синтаксическую едини- цу, любое грамматическое соединение полнозначных слов $[10$, с. 339].

В составных наименованиях может иметь место семантическое выветривание, то есть каждый элемент комплекса как бы теряет свое основное лексическое значение и одновременно служит для выражения единого значения всего комплекса. Для составных наименований в диалектах селькупского языка характерна относительная цельнооформленность. Это значит, что между элементами комплекса невозможно вставить другие слова. Но первый компонент может варьироваться, например, это может быть существительное в именительном или родительном падеже или прилагательное $[4$, с. 38,41$]$.

Цель данной статьи - произвести структурный анализ составных наименований и словосочетаний рыболовной тематики диалектов селькупского языка и выявить основные модели их формирования.

Источниками лексического материала для настоящего исследования явились «Sölkupisches Wörterbuch aus Aufzeichnungen von K. Donner, U.T. Sirelius und J. Alatalo» [12], «Селькупско-русский диалектный словарь» [9] и «Südselkupisches Wörterbuch von N.P. Grigirivski» [13]. Отбор лексического материала, относящегося к северным диалектам селькупского языка, произведен из работ: «Словарь селькупско-русский и русско-селькупский» [2], «Nordselkupisches Wörterbuch von F.G. Mal'cev» [11] и 
«Русско-селькупский словарь. Разнопрофильные селькупские словари» [7].

В результате выборки лексических единиц было выявлено 67 составных наименований и 25 словосочетаний. Необходимо отметить, что классификация сложных комплексов на составные наименования и словосочетания осуществлялась в соответствии с материалами «Селькупско-русского диалектного словаря» [9]. Сложные комплексы, взятые из других источников, были отнесены к той или иной категории по аналогии с номинативными единицами из «Селькупско-русского диалектного словаря». Рассмотрим поочерёдно имеющиеся примеры тех и других.

1) Составные наименования:

таз. қэлытчий қум, тур. қыльчиль қуп, кет. қвӭлай қум, вас. қвэлӭштӭл қуп 'рыбак' < қэлытчи-/қыльчи-/қвӭла-/ қвэлӭштӭ- + й/л(ь) (словообраз. суффикс отн. прил.) 'рыболовный' /'рыбный' + қум/ қуп 'человек';

кет. қвӧлэльди் қум, об. Ш қвӭлжи்ди் қуп қвӭлынжи் қуп 'рыбак' < қвӧлэ-/ қвӭлжй-/қвӭлы- + льди்/ди்/нжй (суффикс прич. I) 'рыбачащий' + қум/ қуn 'человек';

об. Ш қвӭли қвадэрти қуп 'рыбак' < қвӭли 'рыба' + қвадэр + mu் (суффикс прич. І) 'добывающий' + қуn 'человек' = букв. 'рыбу добывающий человек'

таз. ӱтый комя 'прорубь' < ӱm-ы 'вода' + й (словообраз. суффикс отн. прил.) + комя 'колодец' = букв. 'водяной колодец';

таз. näkätsa poqqy, ел. накатсы поқ 'невод' < näkät-/ накат- от глагола näkätqo 'тянуть' + sa/cы (суффикс орудия действия) $[6$, с. 28] + poqqy/nок 'сеть' = букв. 'сеть, которую тянут';

тым. ӱңгӭл ма̄нчm 'котец' < ӱңг̈̈ 'котец', 'юнга' + л (словообраз. суффикс отн. прил.) + ма̄нч-m, возможно, имеет отношение к глаголам об. манчӛгу 'взглянуть', 'посмотреть' или тым. манчэйгу 'быстро взглянуть';

ел. пиччей нӱм 'жерлица', 'дорожка' < пичче-й скорее от пичя 'щука' нежели от пичь 'топор' + нӱм под вопросом связь с нуймбыгу 'быть открытым', имеется в виду открытая ловушка для рыбы;

об. Ч қуӭл пэди қуӭл пэзял 'жерлица','дорожка' < қуӭл 'рыба' + nэдu пэзял, смысл которого неясен, тем не менее связь с об. С пэзुе 'чебак' более вероятна, чем с об. ч пэди 'топор';

ел. қанэрий пок 'мутник' < этимология первого элемента не выявлена, второй элемент пок имеет значение 'сеть';

таз. tētty utyl' poqqy 'сеть-сороковка' < tētty 'четыре' + uty 'рука' + l' (словообраз. суффикс отн. прил.) + роqqу 'сеть' = букв. 'сеть для четырёх рук' [4, с. 42];

таз. pōl qajar 'вентерь' < ро̄ 'палка', 'прут' + I (словообраз. суффикс отн. прил.) + qара $+r$ (словообраз. суффикс сущ.) 'морда' = букв. 'морда из прутьев';

таз. kynsa poqqy 'ставная сеть' < kyn от kyntyqo 'поставить сеть' + sa (суффикс орудия действия) $[6$, c. 28] + роqqy 'сеть';

таз. kintipso poqqy 'пущальня' < kinti от kyntyqo 'поставить сеть' + pso (суффикс орудия действия) $[6$, c. 28] + poq9у 'сеть';

об. kýlza бokka 'плавичная сеть' < первый элемент kýlza имеет в составе прасамодийский элемент ${ }^{*} k u$ 'плыть по течению' [5] + бokka 'сеть' = букв. 'сеть, плывущая по течению';

об. наิ́үур мунт бокka'3-х перстная сеть' < нӑ́үур 'три' + мун 'палец' + $m$ (суффикс род. п.) + боkka 'сеть' = букв. 'сеть трёх пальцев';

об. $m \bar{e} m$ мунm боkka '4-х перстная сеть' < mēm 'четыре' + мун 'палец' + $m$ (суффикс род. п.) + боkka 'сеть' = букв. 'сеть четырёх пальцев';

об. kŷмбla мунт боkka '5-ти перстная сеть' < kŷмбla 'пять' + мун 'палец' + $m$ (суффикс род. п.) + боkka 'сеть' = букв. 'сеть пяти пальцев';

об. С тузой поқ 'сеть на карася' < ту от сущ. туд тудо 'карась' + зой (суффикс прил. со значением обладания) [9, с. 339] + поқ 'сеть' = букв. 'сеть с карасём';

кет. варқ сайи поңгы 'ахан, сеть на осетров' < варқ 'большой' + сай 'глаз', 'петля' + и (словообраз. суффикс отн. прил.) + поңгы 'сеть' = букв. 'сеть с большими петлями';

об. kốра̊л бókka, тым. k’ōral bok' 'муксунка' < kốp-å $k^{\prime}$ ör-ə 'муксун' + л I (словообраз. суффикс отн. прил.) + бókka bok' 'сеть' = букв. 'муксунная сеть';

об. куа́үър самоло́к 'самолов на осетра' < kуа́үър 'осётр' + самоло́к 'самолов' = букв. 'осетровый самолов';

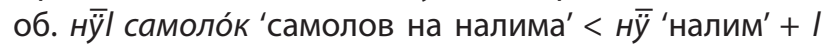
(словообраз. суффикс отн. прил.) + самоло́к 'самолов' = букв. 'налимий самолов';

в.-об. ńük'arbă'то же' < ńй 'налим' + k'arbă'самолов';

об. Ч шӓдыл поққа, тым. šдdel bok '“сырковая сеть' < шӓд-ы šวd-е 'сырок' + л I (словообраз. суффикс отн. прил.) + поққа bok"сеть';

в.-об. n'odei tu'dska karbă 'самолов на стерлядь' < $n$ 'дde 'стерлядь' + i (словообраз. суффикс отн. прил.) + tu'dska, этимология которого затемнена + karbă 'самолов';

тым. tšakal' pok 'кривда для ловли щук' < первый элемент tšakal' не определен, однако суффикс -l' указывает, что это относительное прилагательное + pok 'сеть';

таз. ki'ncyt šè, ki'ncyn šē 'створка запора' < ki'ncy 'запор' + t/n (суффикс род. п.) + še 'язык';

тур. canыm nō'удилище' < сапык'удочка' + $m$ (суффикс род. п.) + nō 'палка' = букв. 'палка удочки';

об. Ч шабӭт пакка шабыт паққа 'удилище' < шабық шаб̈̈қ 'удочка' + $m$ (суффикс род. п.) + пакка паққа 'черенок', 'рукоятка' = букв. 'рукоятка удочки';

об. С сыбызӛн то̄аа 'бородка крючка' < сыбық 'крючок' + दӭн (суффикс локатива) + то̄ца 'бородка' = букв. 'бородка на крючке';

об. С сыбыцӭн калёсӭ 'ушко крючка' < сыбық 'крючок' + दӭн (суффикс локатива) + калёсӭ 'колесо' = букв. 'колесо на крючке'; 
таз. lōmpyl laka 'круглый поплавок' < lōmpy 'поплавок' + I (словообраз. суффикс отн. прил.) + laka 'комок' = букв. 'поплавковый комок' [1, с. 20];

вас. поқот қазаллага 'круглый поплавок' < поқ-о 'сети' $+m$ (суффикс род. п.) + қазал 'короткий', 'большой палец' + лага 'нечто круглое,',шарик' = букв. 'шарик сети';

об. Ч ша̄бық амбалжӭбо 'грузило,' ‘поплавок' < ша̄бық 'крючок' + амбалжӭбо, который имеет общий корень с қамбалымбыгу'плавать,' 'двигаться';

таз. поққыт пӱ 'грузило к неводу' < поққы 'сеть' + $m$ (суффикс род. п.) + пӱ 'камень' = букв. 'камень сети';

ел. поқий ламб 'грузило к неводу' < поқ-и 'сеть' + й (словообраз. суффикс отн. прил.) + ламб 'грузило';

об. С ю 'mmимбыди по́нкъ 'тетива у невода' < пю 'mmu 'тетива' + мбыди (суффикс причастия прош. в.) + по́нкъ 'невод';

кет. t'agī: kŭ'тетива у невода' < t'agī:, возможно, от глаг. тягу 'схватить' + kŭ 'верёвка','повод', 'лямка';

вас. нагӭчӭтӭль чэрмы 'верёвка для невода' < нагӭчӭтӭль (прич. І от гл. нагӭччӭгу 'рыбачить неводом') + чэрм 'верёвка';

тым. pokkanda kōjad 'верёвка для невода' < pokkə-ndə (прич. І от гл. поқыргу 'ловить сетью') + второй элемент kōүəd связан с гл. койетm ӭгу'спрясть';

таз. поққыт пӱры 'кольцо для сети' < поққы 'сеть' + $m$ (суффикс род. п.) + пӱры под вопросом связь с пӱ 'ушко иглы' = букв. 'ушко сети';

таз. поққыт сай, кет. поңгӭн сайи, нар. по́кын сей 'ячейка сети' < поққы поңгӭ по́к'сеть' $+m /$ н (суффикс род. п.) + сай сайи сей 'глаз' = букв. 'глаз сети';

кет. лаппун қӱвӭ 'мульга' < лаппу 'весло' + н (суффикс род. п.) + кӱвӭ 'мозг' = букв. 'мозг весла', т.е. важный элемент;

вас. қолдыт қвӭл қольдыт қвэл 'нельма' < қолды/ қольд-ы 'Обь' + $m$ (суффикс род. п.) + қвӭл қвэл 'рыба' = букв. 'рыба Оби';

кет. чажанди் қвэл 'елец' < чажа-нди் (прич. І от гл. чажгу 'бродить') + қвэл 'рыба' = букв. 'бродячая рыба';

тур. пӱля қылы 'хариус' < пӱ'камень' + ля (умен.-ласкат. суффикс) + қылы 'рыба' = букв. 'камушки рыба'. Такое наименование хариус мог получить из-за того, что водится преимущественно на каменистой отмели рек. Поскольку основу его корма составляют личинки водяных насекомых и водяные улитки, он часто в поисках пищи «тыкает головой в каменья», за что в некоторых местностях, например, на Онежском озере, хариуса называют «кузнецом» [8];

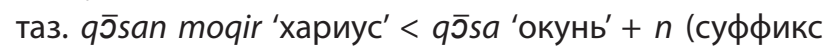
род. п.) + moqir 'спина' = букв. 'спина окуня', очевидно, вследствие наличия огромного спинного плавника спинка хариуса напоминает слегка горбатую спинку окуня [8];

таз. моқалый лэ, об. Ч, вас., тым. мозал лы 'хребет' < моқал-ы 'спина' + й (словообраз. суффикс отн. прил.) / моза-л 'спина' + лэ лы 'кость' = букв. 'кость спины';

кет. қвэлӭн my, тым. kuâl tūd 'плавник' < қвэл-э 'рыба' + н (суффикс род. п.) / kuâl 'рыба' + my tūd 'крыло' = букв. 'рыбье крыло';

об. Ч нюидыл хай, об. С, Ш нюидиं сай 'икринка' < нюидыл нюидиं 'вкусный', 'сладкий' + хай сай 'крупинка' = букв. 'сладкая крупинка';

об. 4 падыт кожа 'желчный пузырь' < пады 'желчь' + $m$ (суффикс род. п.) + кожа 'мешок' = букв. 'мешок желчи'.

\section{2) Словосочетания:}

ел. қарэ четыгу 'забросить сеть' < қарэ 'вниз', 'к воде' + четыгу чяжугу 'забросить (сеть)' = букв. 'вниз бросить сеть';

таз. poqqyp pinqo 'забросить сеть' < poqqy 'сеть' $+p$ (суффикс вин. п.) + pinqo 'положить' = букв. 'положить сеть';

тур. поқӭ кыбыля сайсӭ 'сеть с мелкими/узкими ячейками' < поқӭ 'сеть' + кыбыля 'маленький', 'мелкий' + сай 'ячея' -сӭ (суффикс совмест. п.) = букв. 'сеть с маленькой ячеей';

тым. арӭгӭл поқ 'сеть с мелкими/узкими ячейками' < арӭгӭ, вероятно, от глаг. арэлгу 'связать' + л (словообраз. суффикс отн. прил.) + поқ 'сеть' = букв. 'вязаная сеть';

тым. поқэ челӭмла 'ловушка' < поқэ 'сеть' + под вопросом связь челӭм-ла с гл. челымгу 'родить' + ла (словообраз. суффикс сущ.);

таз. qēlili opči (n) 'черпак', 'ковш' < qēli 'рыба' + I (словообраз. суффикс отн. прил.) + орс̌ 'ковш' + (n) (словообраз. суффикс сущ.) = букв. 'рыбий ковш','ковш для рыбы';

таз. ulqal opči $(n)$ 'черпак', 'ковш' < ulqa 'лёд' + I (словообраз. суффикс отн. прил.) + орс̌ 'ковш' + (n) (словообраз. суффикс сущ.) = букв. 'ледяной ковш','ковш для льда';

тым. ulk'o sōtsa 'ковш', 'черпак' < ulk'o 'лёд' + sōt-sa восходит к глаголу сотmыгу 'черпать' + sa (суффикс орудия действия) $[6$, с. 28] = букв. 'черпак для льда';

об. С сыбызӛн эгӟ 'бородка крючка' < сыбық 'крючок' + दӭн (суффикс локатива) + Эг̈̈, вероятно, - фонетический вариант то̄за 'бородка';

тым. перӭл по 'палка глушить рыбу' < перӭл, возможно, имеет отношение к перелжӛгу'дать' + по'палка', 'прут';

об. Ч фитнильт тӯ'крыло фитиля' < фиітиль 'фитиль' + $m$ (суффикс род. п.) + ту 'крыло';

об. Ч фиітильт шэ 'язык фитиля' < фиітиль 'фитиль' + $m$ (суффикс род. п.) + шэ 'язык';

об. С карбай по 'сошка для самолова' < карба 'самолов' + й (словообраз. суффикс отн. прил.) + по 'палка', 'прут' = букв. 'самоловная палка';

кет. нырсай қвӭл 'мелкая рыба', 'мелочь' < нырса 'ёрш' + й (словообраз. суффикс отн. прил.) +қвӭл 'рыба' = букв. 'ершовая рыба';

таз. тырый қэлы 'икристая рыба' < тыр-ы 'икра' + й (словообраз. суффикс отн. прил.) + қэлы 'рыба';

ел. сэқый қылеймы 'белая рыба' < сэқы-й 'белый' + қыле 'рыба' + ймы (суффикс собирательной множественности) [9, c. 319];

тым. тязӛ тут, об. 4 тяя тут 'серебристый карась' < тязӭ тяз 'белый' + mуm 'карась' = букв. 'белый карась'; 
вас., тым. қво̋лэт қап, кет. қвӧлан қам 'чешуя рыбы' < қвӧл-э/а'рыба' + m/н (суффикс род. п.) + қап қам 'чешуя';

об. С қвэлнан сйца, об. С квэлэн шиза 'рыбий пузырь' $<$ қвэл квэл-э 'рыба' + нан (суффикс локатива для одуш. сущ.) / н (суффикс род. п.) + сйदа шиदа 'пузырь';

таз. қэлын ӱр, вас. қво̋лан о̋р, кет. қво̋лан юр 'рыбий жир' < қэл-ы қвӧл- $а$ 'рыба' + н (суффикс род. п.) + урр юр ӧр 'жир'.

Проведённый структурный анализ сложных комплексов выявил следующие модели их построения. Для двухкомпонентных составных наименований в большинстве случаев характерны схемы образования:

1. существительное (им., род., или мест. п.) + существительное (им. п.);

2. относительное прилагательное + существительное (им. п.);

3. причастие (наст. или прош. в.) + существительное (им. п.).

Трёхкомпонентные составные наименования образуются по моделям:

1. числительное + относительное прилагательное + существительное;

2. числительное + существительное (им. п.) + существительное (им. п.);

3. прилагательное + прилагательное + существительное (им. п.).

Среди словосочетаний встречаются глагольные ком- плексы, в которых главное слово выражено глаголом, а второстепенное слово существительным (вин. п.) или наречием, а также именные комплексы, в которых главное слово представлено существительным (им. п.), а второстепенное - либо относительным прилагательным, либо существительным, чаще в род. п.

В целом, образование сложных комплексов является важным способом обогащения селькупской лексики рыболовства. Они используются для обозначения наиболее специфичных реалий рыболовства, характерных для селькупского хозяйственного уклада: орудий рыбного лова и их компонентов. Образование сложных комплексов происходит, как правило, на основе лексем, выражающих общеизвестные рыболовецкие понятия: 'невод', 'сеть', 'удочка' и 'рыба'. Структурный анализ помог установить, что для составных наименований характерны 6 моделей образования, для словосочетаний - 4 модели.

\section{Сокрашения}

Вас. - васюганский диалект; в.-об. - вехнеобские говоры; ел. - елогуйский диалект; кет. - кетский диалект; нар. - нарымский диалект; об. - обские говоры; об. С обские говоры Сюсюкум; об. Ч - обские говоры Чумылькуп; об. Ш - обские говоры Шёшкум; таз. - тазовский диалект; тур. - туруханский диалект; тым. - тымский диалект.

\section{ЛИТЕРАТУРА}

1. Дубровская Н.В. Организация семантической структуры селькупских лексем (на примере вас., кет., тым. laga, laya; таз. laka) / Н.В. Дубровская, А.А. КимМалони // Томский журнал ЛИНК и АНТР. - Томск: ТГПУ, 2019. - № 4 (26). - С. $17-27$.

2. Ириков С.И. Словарь селькупско-русский и русско-селькупский: Около 4000 слов: пособие для учащихся начальной школы / С.И. Ириков - Л.: Просвещение. Ленингр. отд-ние, 1988. - 224 с.

3. Копылова Э.В. Терминологические словосочетания в рыболовецкой лексике Волго-Каспия / Э.В. Копылова // Вопросы теории и методики русского языка. - Ульяновск: [б. и.], 1969. - С. 119-127.

4. Кузнецова А.И. Очерки по селькупскому языку. Тазовский диалект / А.И. Кузнецова, Е.А. Хелимский, Е.В. Грушкина. - М.: МГУ, 1980. - Т. 1. - 408 с.

5. Норманская Ю.В. Некоторые причины семантических изменений (на материале генезиса и развития системы глаголов плавания в селькупском языке) / Ю.В. Норманская, Н.Л. Красикова // Урало-алтайские исследования. - М.: Институт языкознания РАН, 2009. - № 1. - Режим доступа: https://iling-ran.ru/ Normanskaya/normanskaya/15.pdf (дата обращения 01.11.2020).

6. Прокофьев Г.Н. Селькупская грамматика / Г.Н. Прокофьев. - Л.: Изд-во Ин-та народов Севера ЦИК сССР, 1935. - 131 с.

7. Русско-селькупский словарь. Разнопрофильные селькупские словари / О.А. Казакевич, А.И. Кузнецова, Е.А. Хелимский; под ред. А.И. Кузнецовой. - М.: МГУ, 2002. - Т. 3. -219 с.

8. Сабанеев Л.П. Рыбы России. Жизнь и ловля (ужение) наших пресноводных рыб [Электронный ресурс] / Л.П. Сабанеев. - 1892. - Т. 1. - Режим доступа: https://www.sabaneev.org/наследие/рыбы-россии-1/ (дата обращения 20.08.2020).

9. Селькупско-русский диалектный словарь / В.В. Быконя, Н.Г. Кузнецова, Н.П. Максимова; под ред. В.В. Быконя; Федеральное агентство по образованию, Гос. образоват. учреждение высш. проф. образования Томский гос. пед. ун-т. - Томск : Том. гос. пед. ун-т, 2005. - 347 с.

10. Словарь лингвистических терминов / Т. В. Жеребило. 5-е изд-е, испр. и доп. - Назрань : Пилигрим, 2010. - 486 с.

11. Helimski E. Nordselkupisches Wörterbuch von F. G. Mal'cev / Hrsg. von E. Helimski, U. Kahrs. - Hamburg : Universität Hamburg, 2001. - 155 S.

12. Lexica Societatis fenno-ugricae. 30: Sölkupisches Wörterbuch aus Aufzeichnungen von K. Donner, U. T. Sirelius und J. Alatalo / zsgest. u. hrsg. von J. Alatalo. - 
Helsinki : Finnisch-Ugrische Gesellschaft, 2004. - Bd. 27. - 465 S.

13. Südselkupisches Wörterbuch von N. P. Grigorovski / Bearbeitet und hrsg. von E. Helimski. - Hamburg : Inst. für Finnougristik/Uralistik der Universität Hamburg, 2007. -225 S.

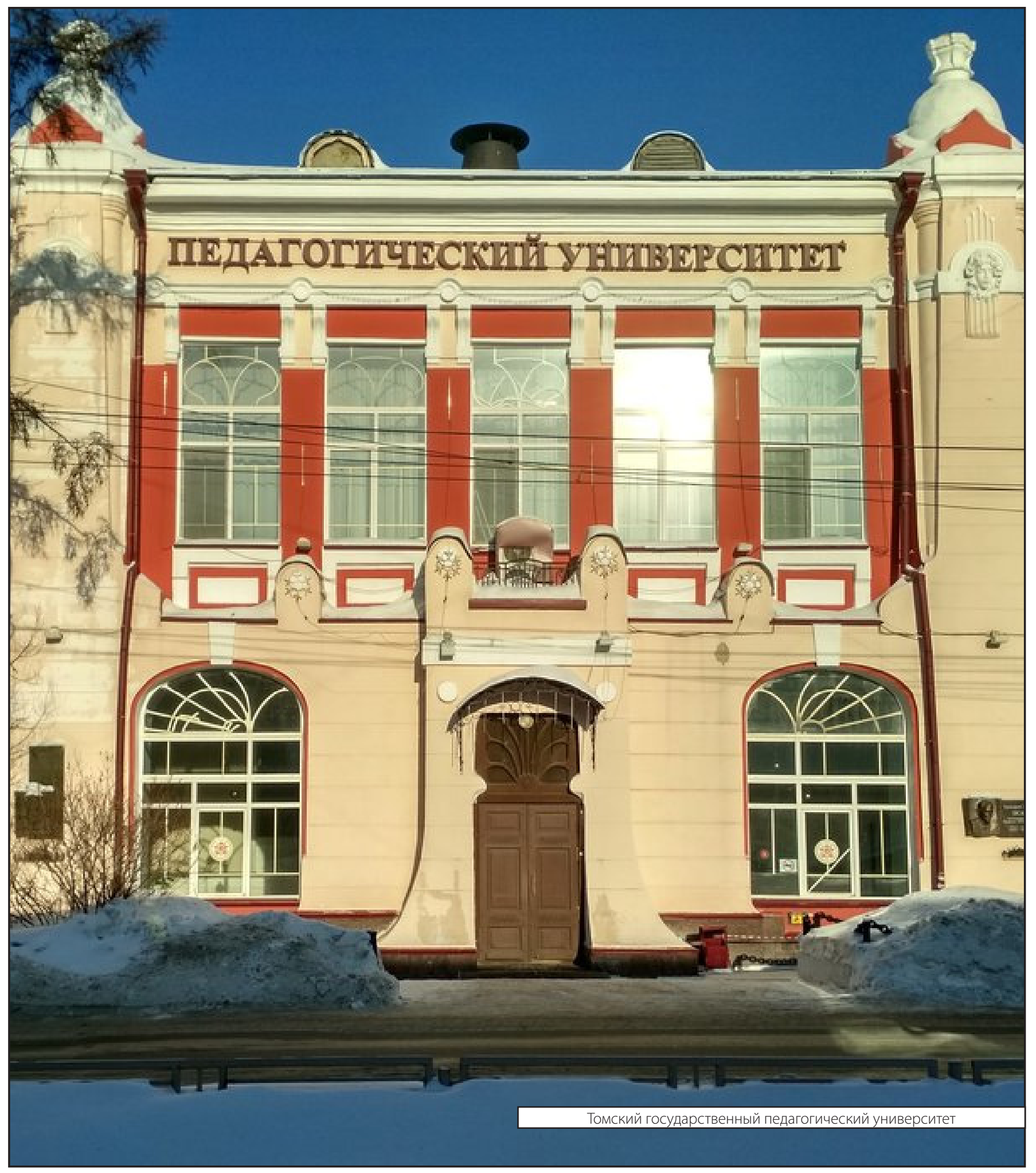

